\title{
GASES DEL ABDOMEN SU UTILIDAD DIAGNOSTICA: GASES ENDOLUMINALES (SEGUNDA PARTE)
}

\author{
Dr. Claudio Cortés A.
}

Servicio de Radiología. Hospital Clínico Universidad de Chile. Departamento de Imagenología. Clínica Alemana, Santiago.

\begin{abstract}
The plain abdominal radiograph provides the first standard imaging method and sometimes the only exam for diagnosis of swallowed or introduced foreign bodies through natural or artificial ways. Plain films are still very useful in acute abdomen when hollow visceral perforation is suspected and free air is being searched. Also plain films in intestinal obstruction are useful. There are characteristic images in abdominal radiograph of ileus toxic megacolon and obstruction in hernia sacs.

Images produced by endoluminal gases are analyzed with particular emphasis on its amount, from complete absence of gases to great trapped volumes.

Images were provided from the Radiology Department of Hospital Clínico J.J. Aguirre University of Chile, Clínica Indisa, Clínica Alemana and Scanner San Vicente de Paúl.
\end{abstract}

Key words: Endoluminal gases, Abdomen, Plain film.

Resumen: La radiografía simple del abdomen sigue siendo un paso inicial y a veces el único examen de imágenes necesario para diagnosticar cuerpos extraños; ingeridos o introducidos por orificios naturales $o$ artificiales, voluntaria o involuntariamente. Es muy útil en abdomen agudo, cuando se sospecha rotura de víscera hueca y se busca el pneumoperitoneo o en obstrucciones del tubo digestivo alto o bajo en donde se investigan asas dilatadas y eventuales niveles hidroaéreos. Hay imágenes características de la radiografía simple en vólvulos cólicos, megacolon tóxico y obstrucciones en sacos herniarios.

Cortés C. Gases del abdomen su utilidad diagnóstica: Gases endoluminales (segunda parte). Rev Chil Radiol 2002; 8: 107 - 118.

* Primera parte. Rev Chil Radiol 2002; 8:5-12.

Correspondencia: Dr. Claudio Cortés A.

Casilla 198 correo 12. Santiago Chile.

claudiocor@hotmail.com
Se analizan las imágenes producidas por los gases endoluminales poniendo atención a su cuantía, desde la ausencia de gas abdominal hasta el atrapamiento de grandes volúmenes.

Las imágenes aportadas provienen de pacientes atendidos en el Hospital Clínico de la Universidad de Chile, Clínica Indisa, Clínica Alemana y Scanner San Vicente de Paúl.

Palabras claves: Gases endoluminales, Abdomen, $R x$ simple.

\section{Malrotación}

Las malrotaciones congénitas generales o limitadas del intestino, pueden ser diagnosticadas en radiografías (Rx) simples mirando la distribución de los gases (Figuras 1,2). La clave en la detección de las malrotaciones del intestino delgado (ID), es la presencia de asas yeyunales con gas en el cuadrante superior derecho del abdomen. El yeyuno normal se sitúa en el abdomen medio a izquierda y el ileon reside en el hemiabdomen inferior en ambos lados, y en la pelvis. El cuadrante superior derecho no debe contener intestino delgado, a menos que esté desplazado por masas o incompletamente rotado. Sabiendo que el gas en el colon transverso es una hallazgo casi constante en placas supinas del abdomen, su ausencia en pacientes sin antecedentes quirúrgicos es sugerente de malrotación.

\section{Cambios post-quirúrgicos, gas gástrico, intestino sin gas}

Obviamente debe ponerse atención a los antecedentes quirúrgicos. Mirar todas las cicatrices y luego interrogar al paciente sobre su origen o telefonear al médico de referencia. La cámara de aire gástrica se modifica en cirugías que intentan corregir el reflujo, en gastrectomías parciales o totales. En el Billroth II, el yeyuno es elevado y unido al remanente gástrico y su ubicación produce imágenes aéreas que hay 


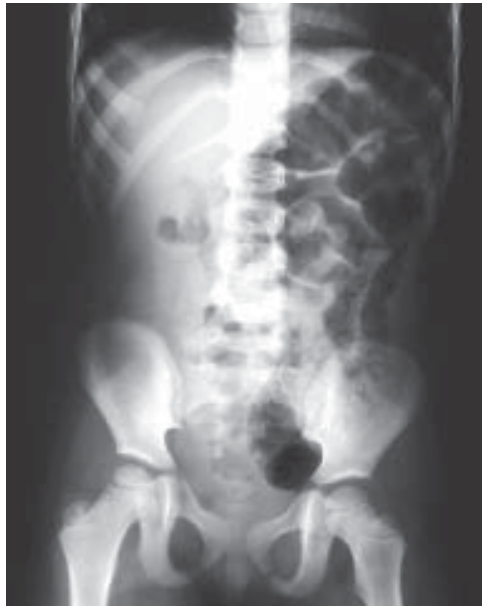

Figura 1. Mesenterio único. Malrotación intestinal.
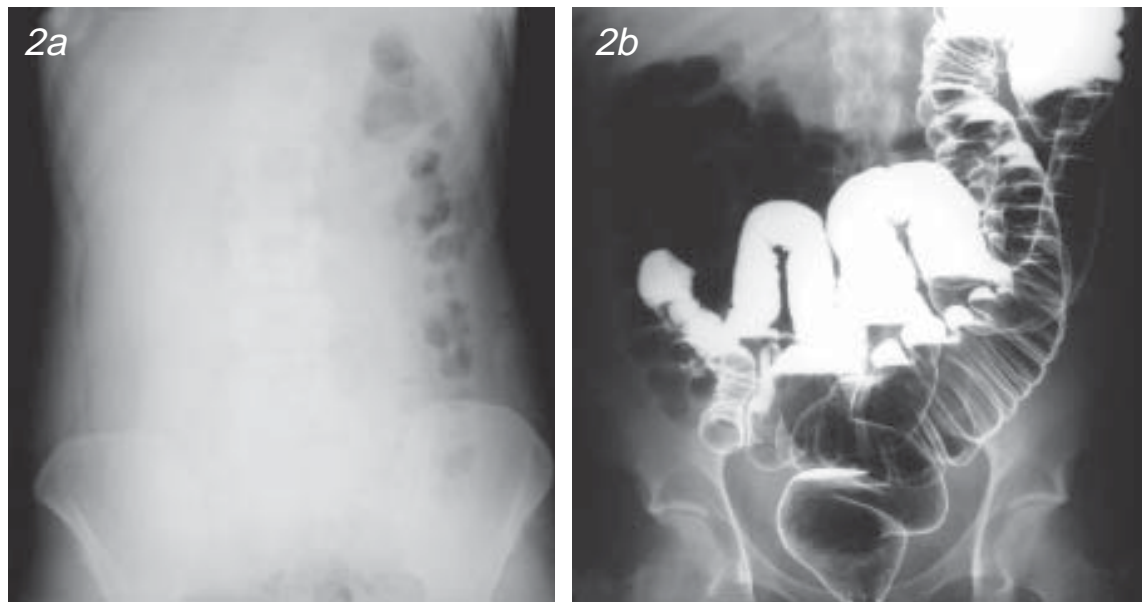

Figuras 2 a,b. Malrotación intestinal a. Abdomen simple. ID sin gas a la derecha y colon a la izquierda. b. Examen contrastado. que interpretar con conocimiento del antecedente quirúrgico. Lo mismo es válido para resecciones parciales o totales del colon.

No se debe intentar interpretar las imágenes sin conocimiento de los antecedentes clínicos, por ejemplo tricofagia (Figura 3). Es necesario poner atención a los clips quirúrgicos, en su ubicación y número. Ellos nos pueden indicar el segmento intervenido y a veces la habilidad del cirujano notada por clips abiertos, caídos al peritoneo o en número excesivo.

Hay que poner atención a la morfología del lumen de la burbuja de aire gástrica. Sus modificaciones con defectos de llenamiento e irregularidades o aumento de la distancia a la cúpula diafragmática en Rx de abdomen e incluso de tórax nos permiten sospechar una cáncer gástrico infiltrativo del fornix (Figura 4). El estrechamiento persistente del lumen debe hacer sospechar linitis. Las úlceras grandes de curvatura menor, ocasionalmente son visibles en placas simples en decúbito dorsal (Figura 5). El volu- men gástrico, aéreo y líquido, con clínica concordante, permite el diagnóstico de dilatación aguda de estómago (Figura 2, primera parte) y la inspección de manos y dientes, en mujeres jóvenes, puede hacer sospechar bulimia.

La ausencia de aire en estómago es orientadora de importantes patologías. La acalasia severa con esófago permanentemente inundado impide la deglución de aire (Figura 6). Pacientes operados de reflujo gastroesofágico, cirugía tan prevalente en nuestros días, cuando están sobrecalibrados, funcionan igual que los acalásicos, con esófagos inundados y pueden no tener gas en estómago ni ID. También los pacientes neurológicos con alteración deglutoria y los que están en ventilación mecánica con nutrición parenteral pueden tener abdómenes sin gas, de igual forma aquellos cuyos intestinos están fuera del abdomen o presentan oclusión alta (Figuras 7,8 ). Los vómitos severos y prolongados, pueden eliminar el gas del abdomen.
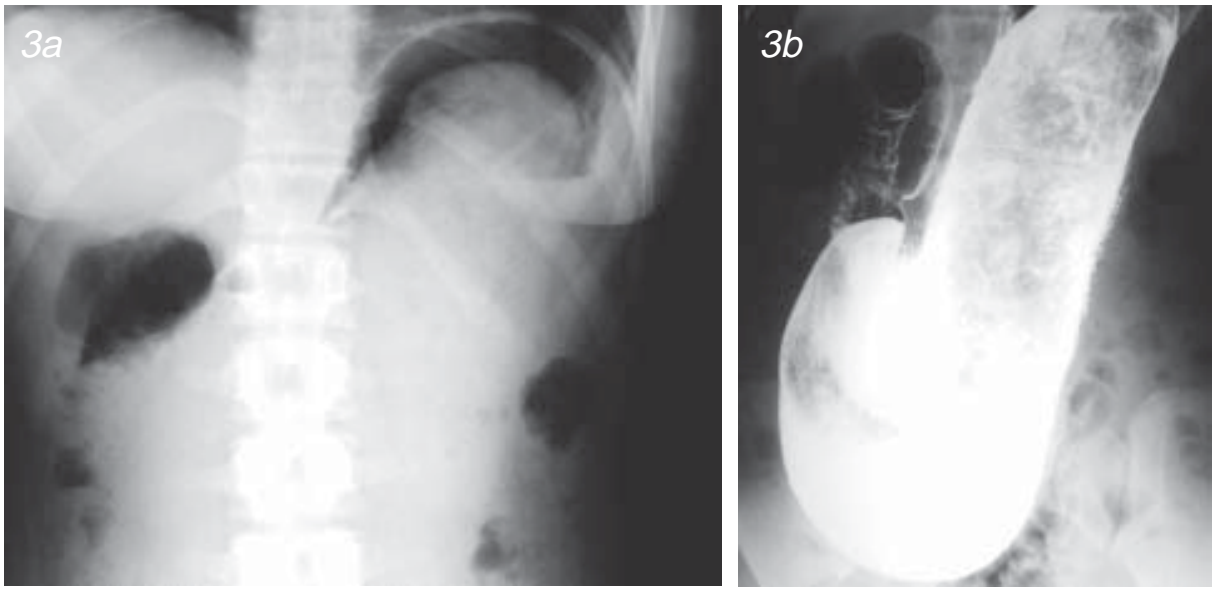

Figuras 3 a-c. Tricobezoar gástrico. a. Abdomen simple c. Pieza quirúrgica.

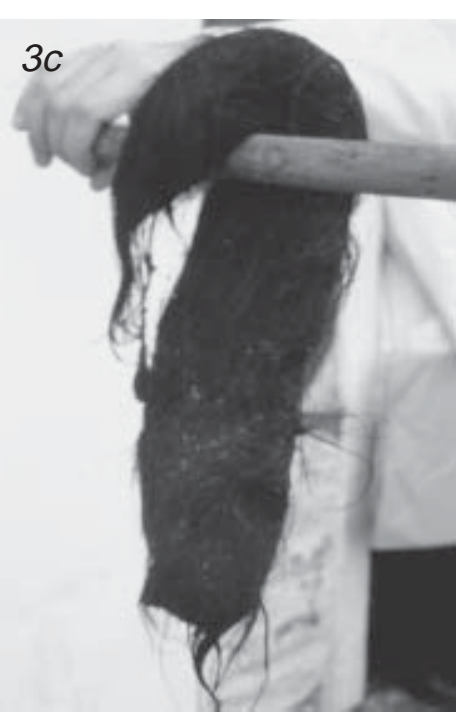



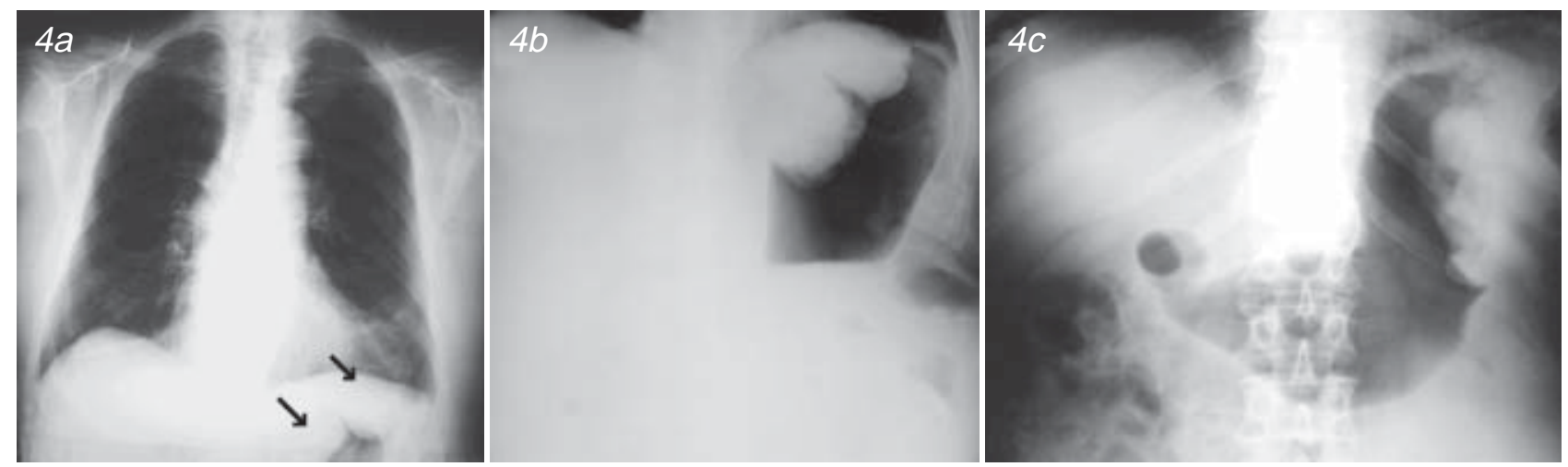

Figuras 4 a-d. Cáncer gástrico a. Rx tórax demostrando en su parte inferior una masa del fondo gástrico. (flechas) b. Visión localizada del abdomen en Rx de tórax. c. Rx abdomen simple AP decúbito. d. Examen contrastado.
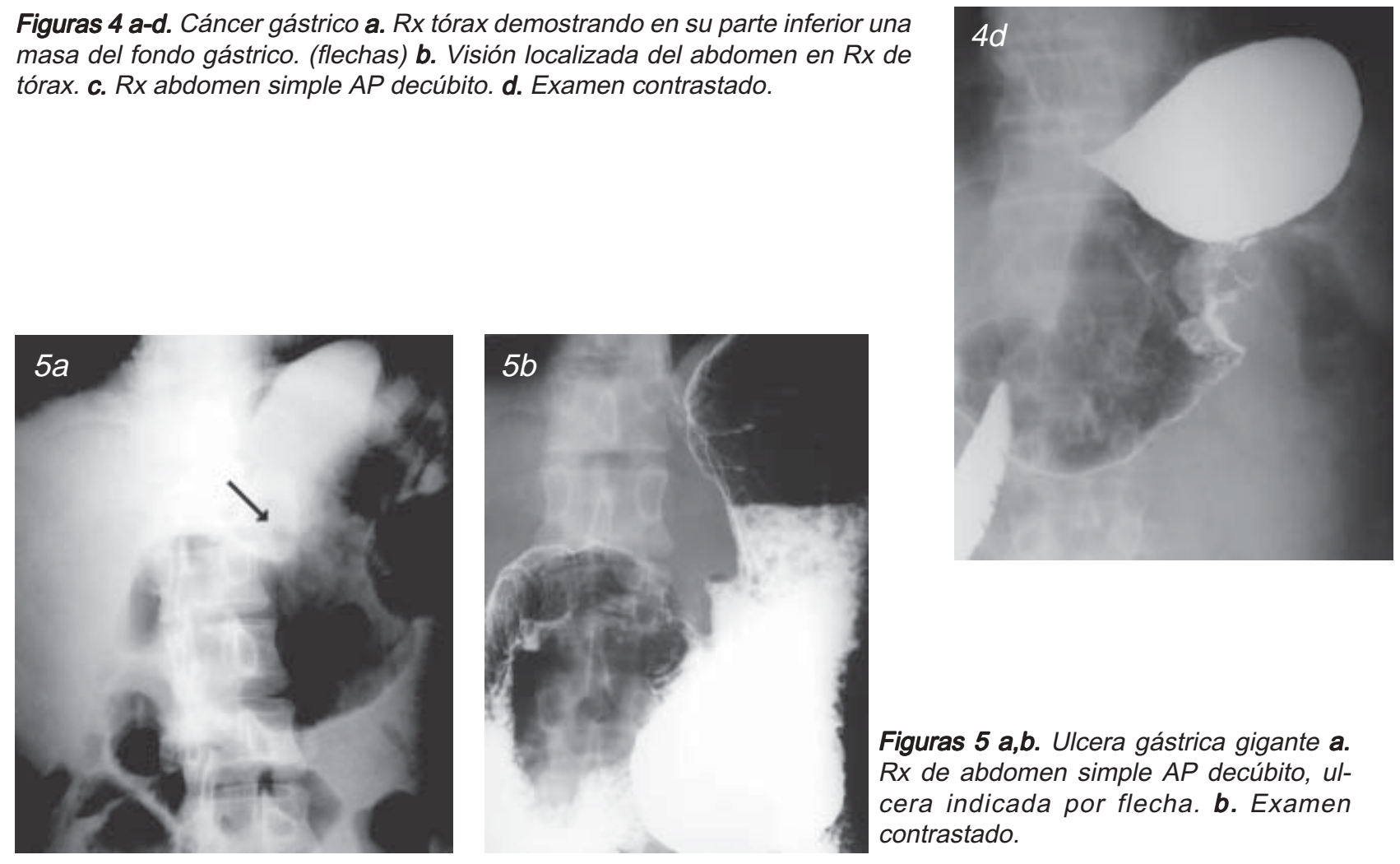

Figuras 5 a,b. Ulcera gástrica gigante a. Rx de abdomen simple AP decúbito, ulcera indicada por flecha. b. Examen contrastado.
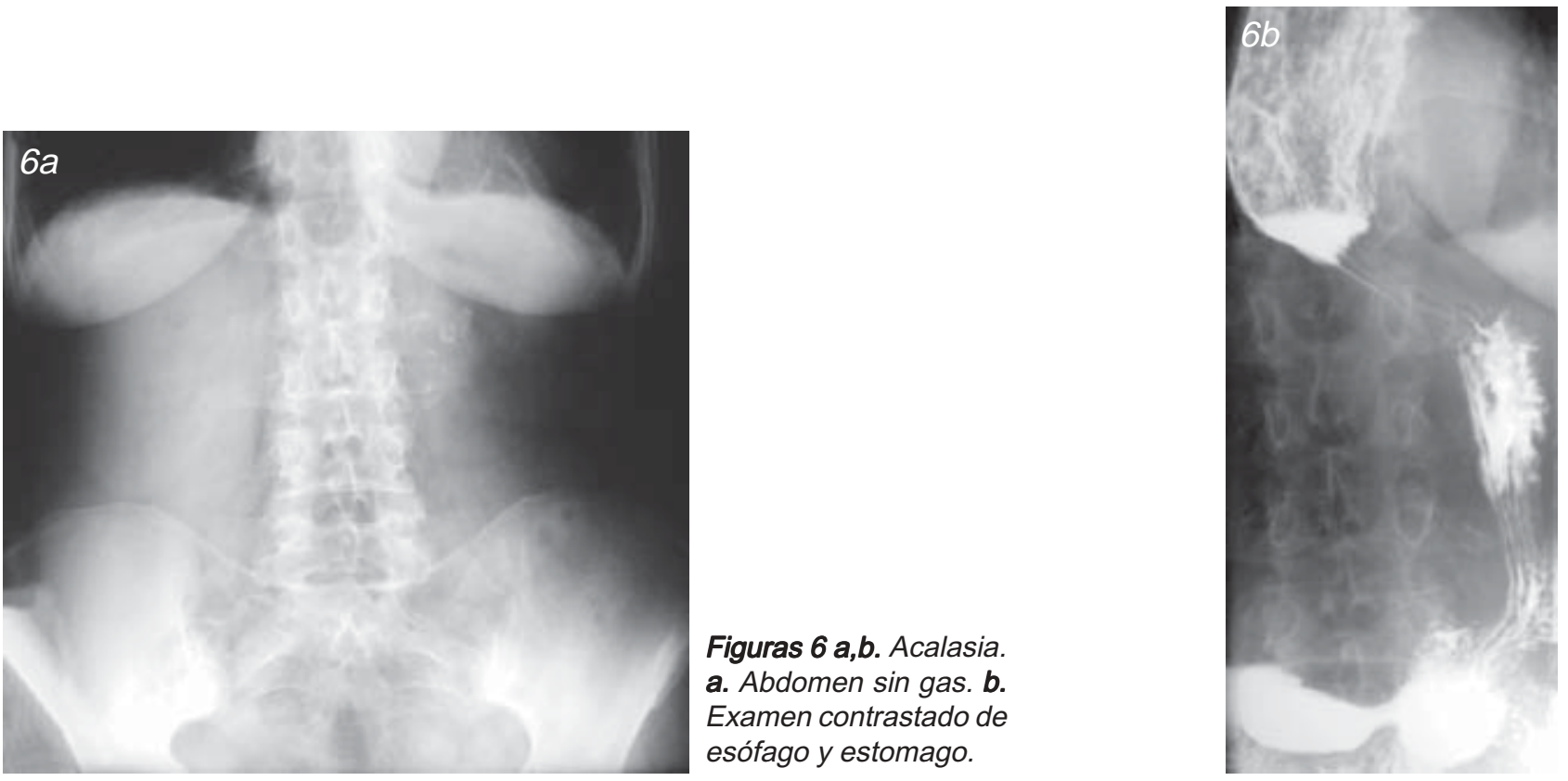


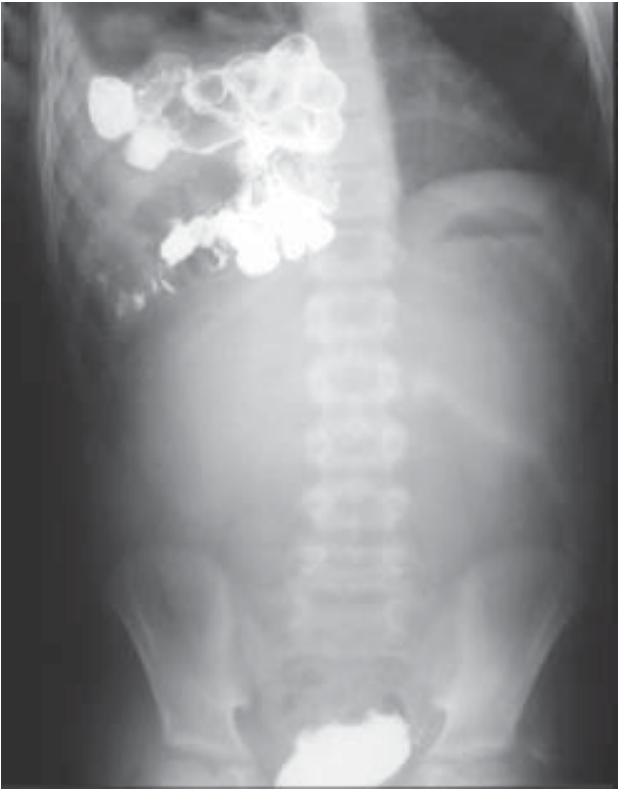

Figura 7. Examen contrastado. Abdomen sin gas. Intestinos en el tórax.

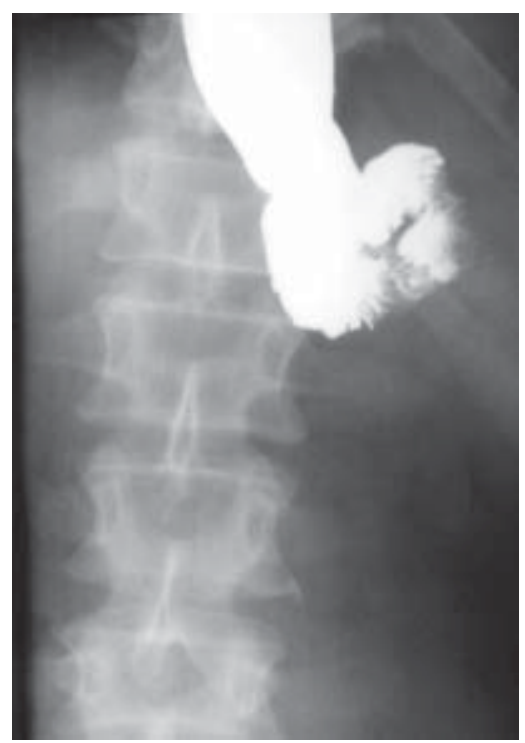

Figura 8. Abdomen sin gas por oclusión yeyunal alta.

Recurrencia de carcinoma en gastrectomizado.

\section{Gas en paciente pediátrico}

Es esperable tener gas en el estómago desde las dos horas de vida, desde las seis en el ID y a las 24 horas en el recto. En recién nacidos se observa abdómenes sin gas en atresia esofágica y en intestinos situados fuera del abdomen tal como ocurre en hernias y onfaloceles.

En lactantes el estómago dilatado se debe a deglución de aire durante el llanto. El estómago dilatado, lleno de aire, persistente, puede deberse a obstrucción del tracto de salida, especialmente si no hay gas distal. Entre las causas de obstrucción del tracto de salida son frecuentes la estenosis pilórica hipertrófica, el píloro-espasmo y membranas antrales, menos frecuentes las duplicaciones quísticas y el tejido pancreático heterotópico.

Cuando hay una doble burbuja aérea hay gas en el estómago y en el bulbo duodenal y poco a nada de gas distal. Ello es indicativo de obstrucción duodenal y sus causas más frecuentes son atresia duodenal (Figura 9) o estenosis, y menos frecuente es el páncreas anular, diafragmas duodenales y vólvulo del intestino medio, que también puede ocurrir en adultos (Figuras 10,11). Siempre que se ve una doble burbuja se debe preguntar ¿El vómito es bilioso?. Si la respuesta es positiva puede tratarse de vólvulo del intestino medio y aunque las otras etiologías son más frecuentes, este hallazgo se debe investigar, ya que no diagnosticarlo implica alta mortalidad.
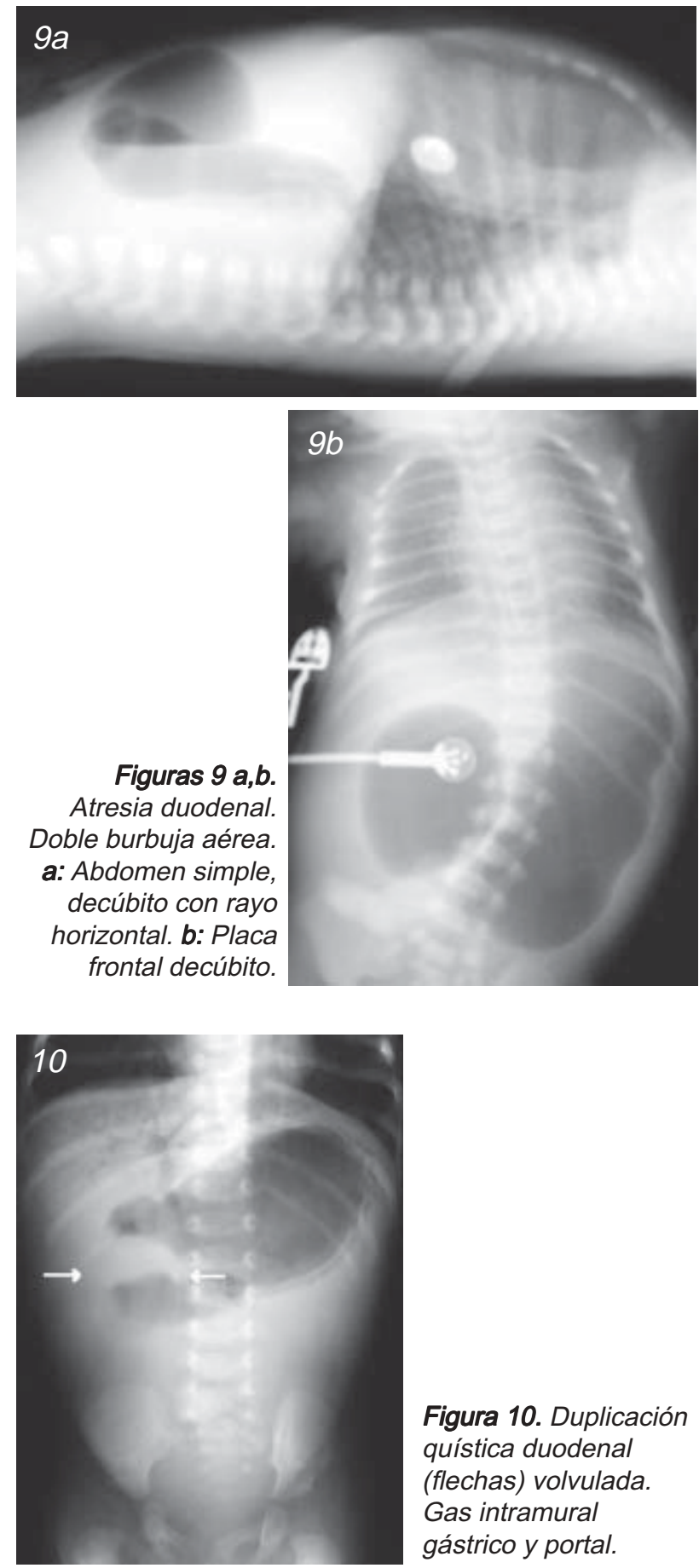

Figura 10. Duplicación quística duodenal (flechas) volvulada. Gas intramural gástrico y portal. 

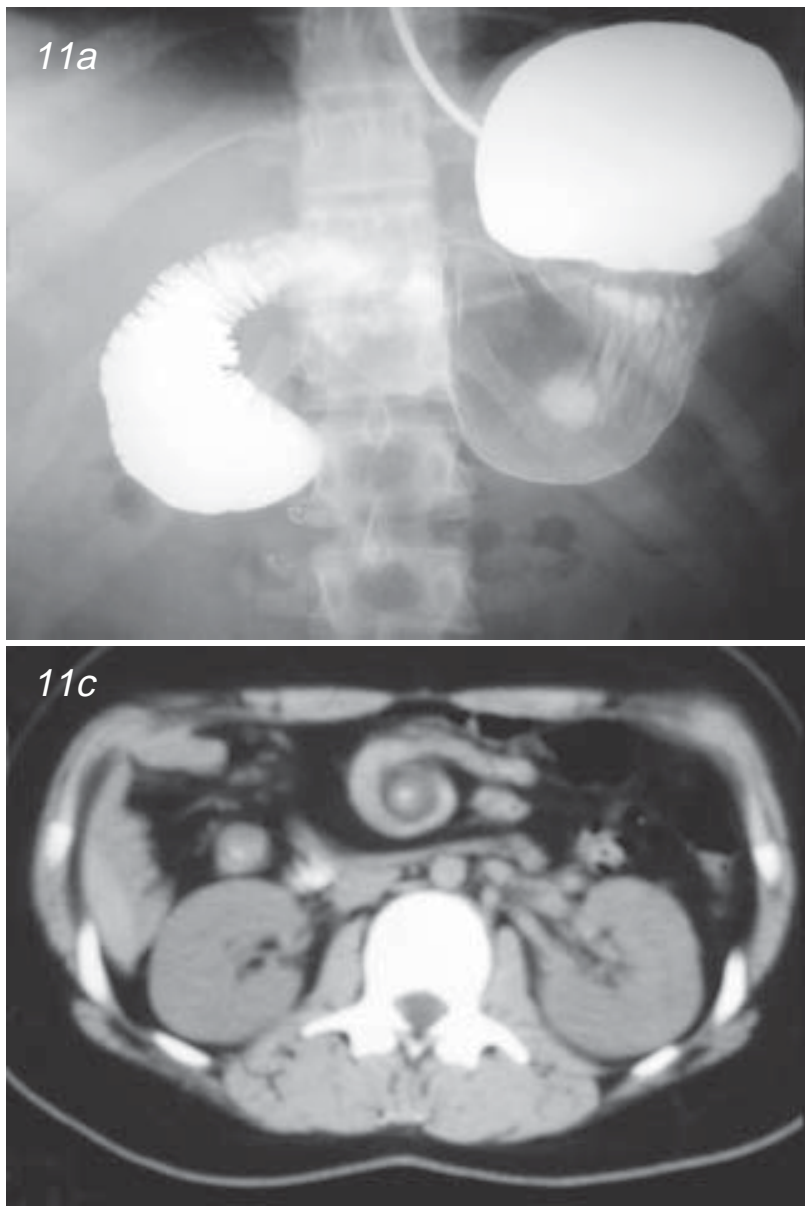

lleo mecánico

Es una de las causas más frecuentes de solicitud de Rx del abdomen de urgencia.

El bloqueo del lumen produce acumulación de jugos intestinales y gas. El intestino se dilata y el peristaltismo es más enérgico en un esfuerzo para propulsar el contenido intestinal hacia distal. Ello motiva los cólicos intestinales y los ruidos hidroaéreos (borborigmos). La Rx simple muestra asas distendidas, radiolúcidas por el gas. La imagen es variable, dependiendo de la cuantía de la obstrucción, de la proporción de líquido y gas en cada segmento de intestino ocluido. Mientras más proximal el bloqueo, menor es el número de asas dilatadas (Figura 12) y por ello la obstrucción de los primeros centímetros del yeyuno puede pasar desapercibida en las Rx simples mientras que las obstrucciones ileales se reconocen fácilmente por gran dilatación intestinal en múltiples asas (Figuras 13,14). Importa el tiempo, porque el gas no se acumula instantáneamente. Mientras mayor el período de obstrucción es mayor la probabilidad de observar dilatación proximal. Esta regla tiene excepciones porque existen las obstrucciones incompletas o intermitentes que permiten descompresión parcial del intestino.

Importa recordar que el gas intestinal de asas obstruidas puede absorberse y eliminarse durante los vómitos. No debe esperarse la existencia de niveles

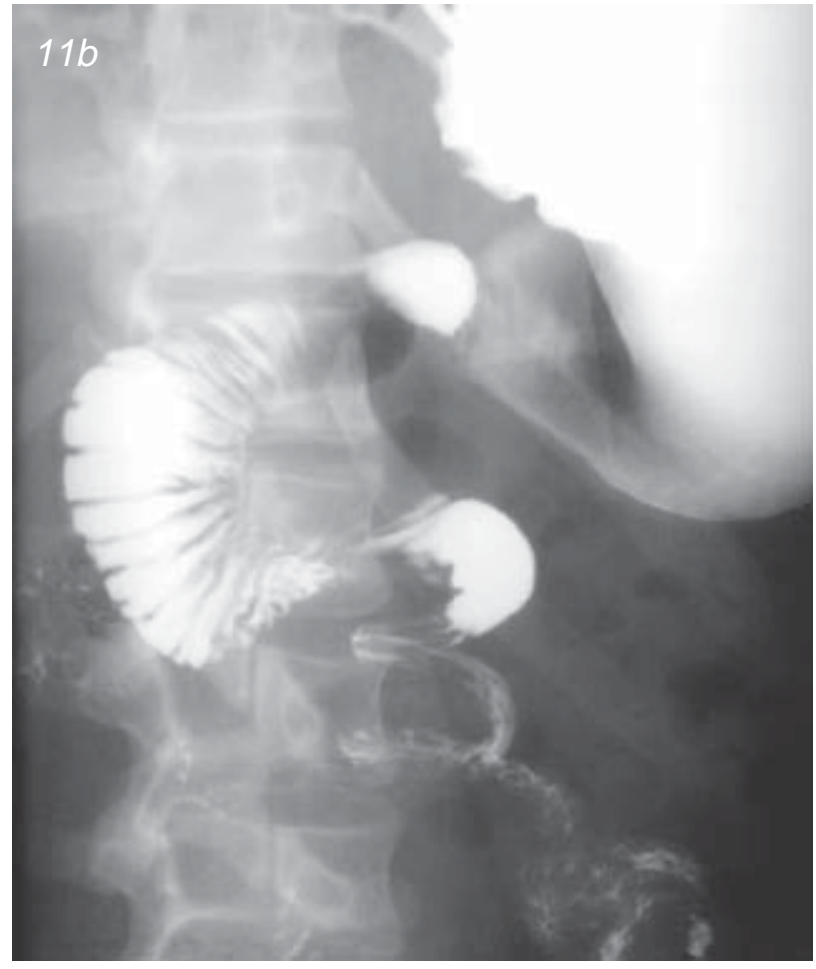

Figuras 11 a-c. Vólvulo del intestino medio a: Examen contrastado. b: Signo de la cáscara de manzana en examen contrastado. c: TAC. Signo del remolino.

hidroaéreos. Después de la etapa del "collar de perlas", las asas obstruidas sólo contiene líquido y si el signo fundamental es la detección de niveles hidroaéreos el paciente morirá y permaneceremos en el paraíso de los tontos (Figura 15).

En obstrucción del ID una cantidad variable de gas ocupa el intestino grueso (IG) haciéndolo individualizable por sus haustras y plicas. En decúbito supino el gas se acumula en el colon transverso y sigmoides por razones gravitacionales. La obstrucción del ID no significa desaparición total e inmediata del gas distal y generalmente demora uno a dos días la evacuación total del gas del colon. Por lo tanto, gas en el colon es esperable en etapas precoces y aún después de la oclusión total, ya que la fermentación del contenido fecal residual, puede producir gas.

En aproximadamente uno de cada cuatro pacientes con obstrucción del IG, la válvula ileocecal incompetente descomprime el colon y los gases cólicos ingresan al íleon, por lo tanto, lo que parece una obstrucción del íleon, puede corresponder a oclusión del colon.

Las obstrucciones mecánicas pueden ser simuladas por diversas patologías: asas dilatadas con gas adyacente a procesos inflamatorios (asas centinelas), isquemias mesentéricas, en que no hay obstrucción del lumen, pero si parálisis funcional de la pared con interrupción del transporte. 

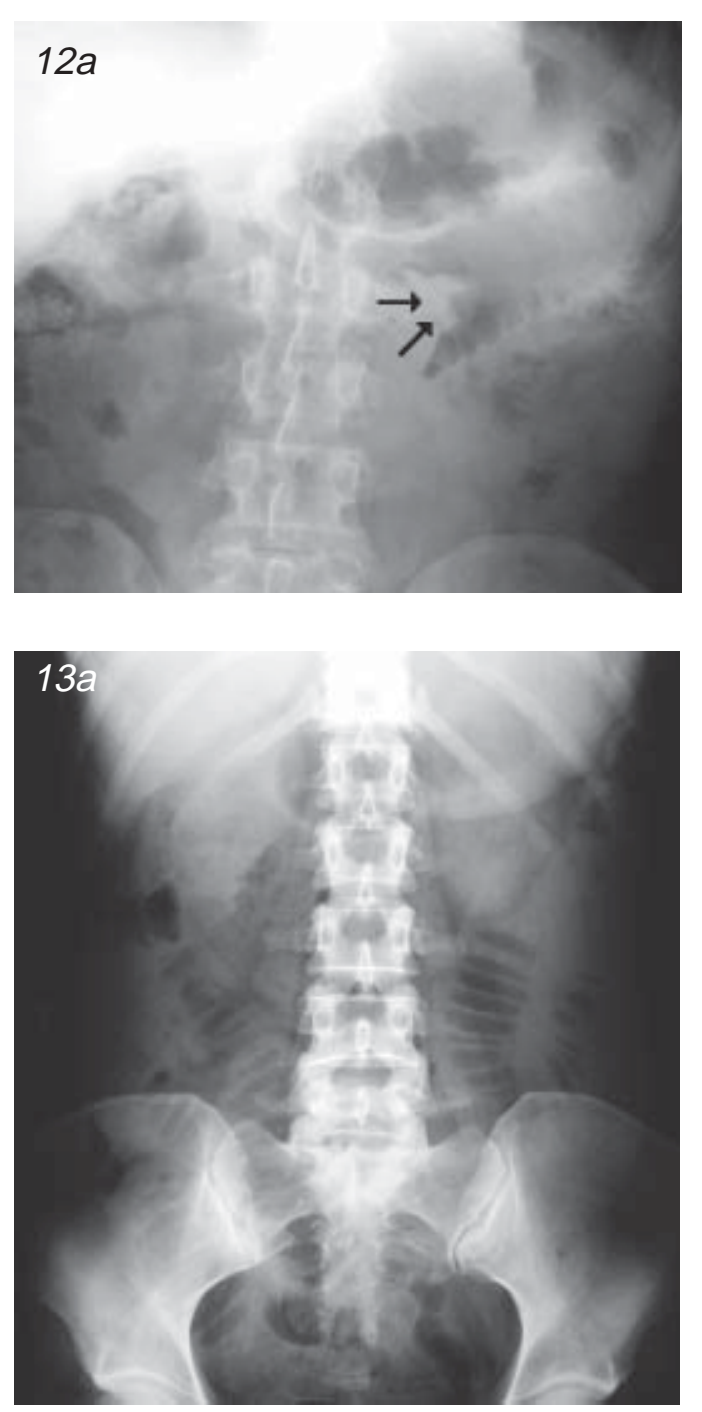

Figuras 12 a,b. a. Abdomen simple. Gastroyeyunoanastomosis. Bezoar (flechas) obturando asa yeyunal anastomótica. $\boldsymbol{b}$. Examen contrastado. Bezoar en asa yeyunal anastomótica (flechas). Hemigastrectomía. Examen contrastado.

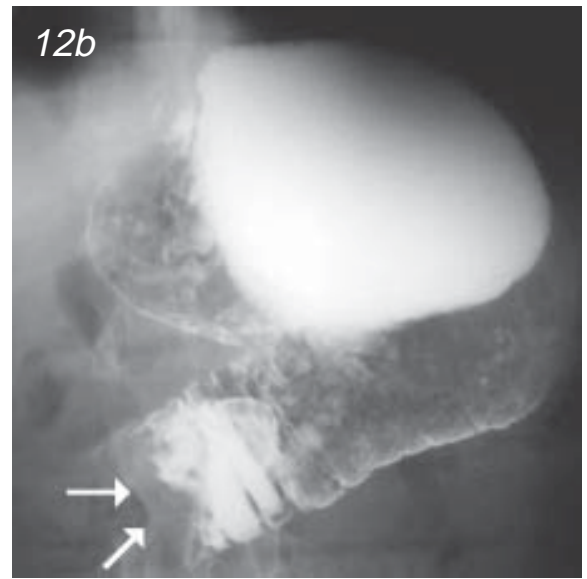

Figuras $13 a, b$. Obstrucción del ID bajo a. Abdomen simple. Múltiples asas dila-tadas. Válvulas conni-ventes estiradas. b. Examen contrastado. Obturación del ID bajo por fitobezoar en paciente con hemigastrectomía.

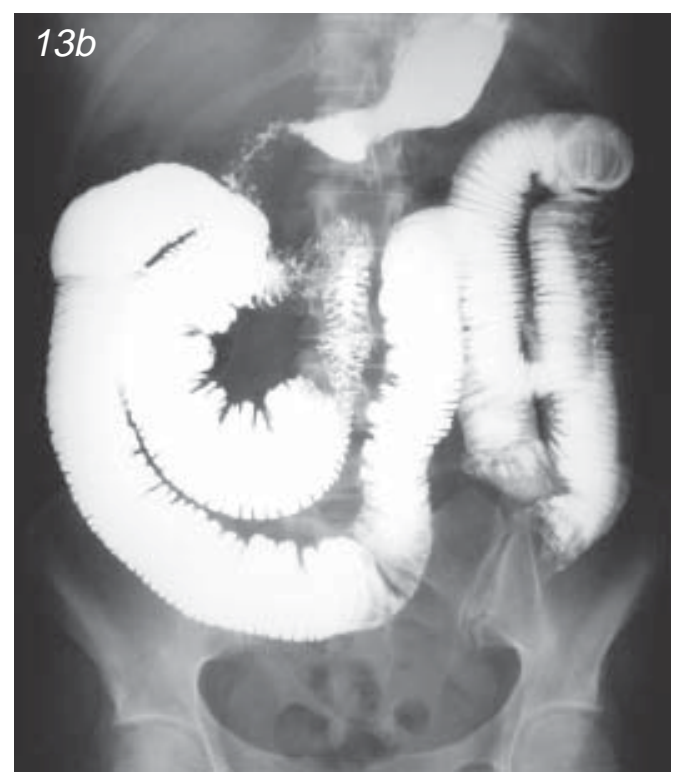

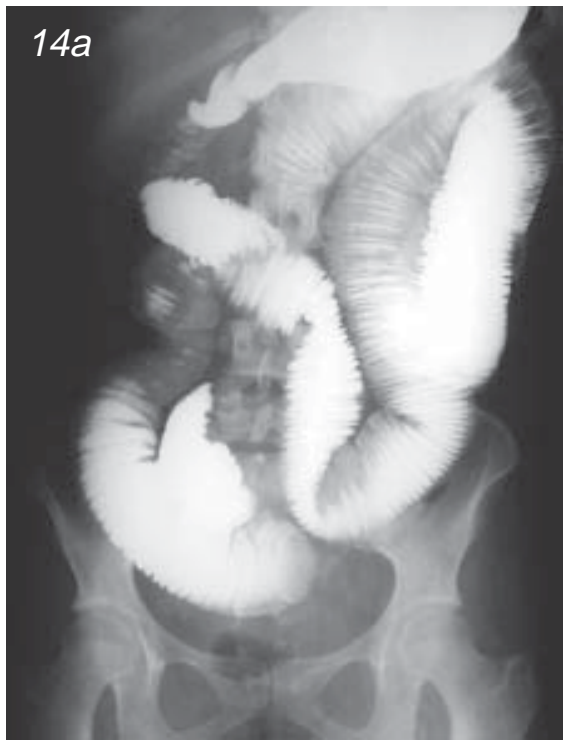

Figura 14. Intestino delgado. Obstrucción yeyunal por brida.

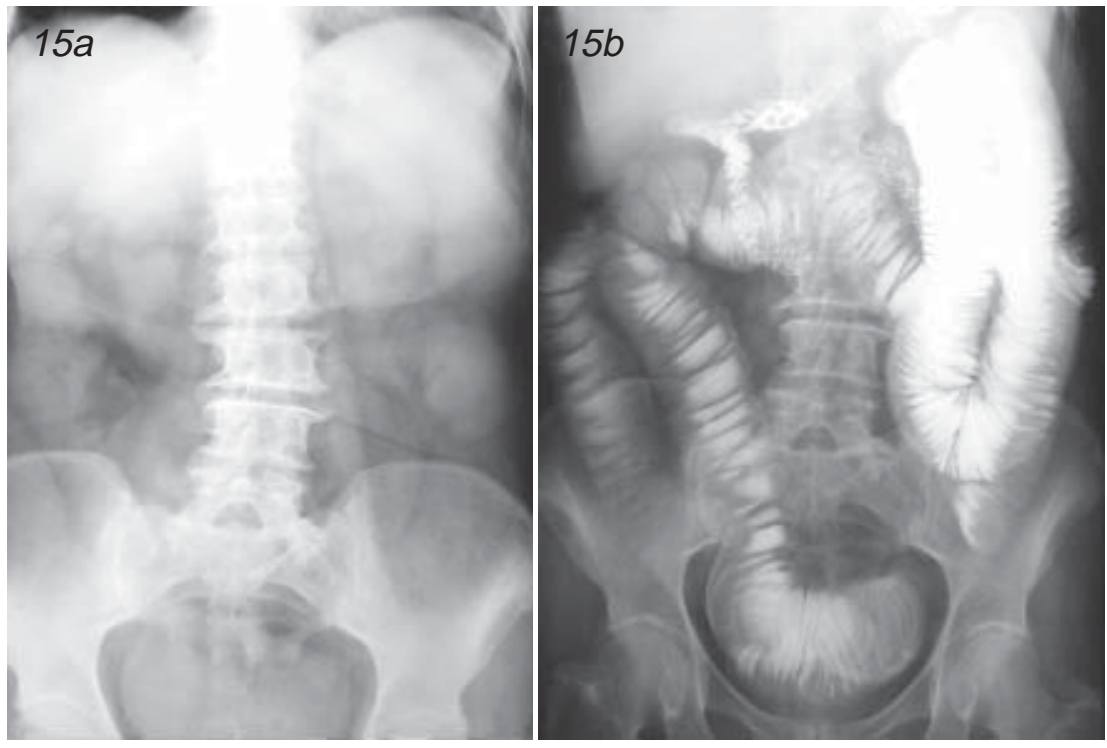

Figuras 15 a,b. Obstrucción intestinal con varios días de evolución. a. Abdomen simple. Se absorbió el gas y no hay niveles. $\boldsymbol{b}$. Rx contratada de obstrucción sin niveles. El paciente fallece durante la cirugía. 
La detección de la obstrucción intestinal tiene limitaciones impuestas por la falta de especificidad y sensibilidad del patrón de obstrucción intestinal. El diagnóstico no puede ser formulado con certeza en todos los casos. La probabilidad de diagnosticar correctamente la obstrucción por placas simples sólo llega al $80 \%$. La correlación con la clínica y el uso de métodos de imágenes como la tomografía computada (TC) y la ecotomografía, son de gran ayuda.

Los íleos adinámicos afectan a ambos intestinos. Pueden estar distendidos con gas y líquido, o sólo con líquido, en este caso, difícil es diagnosticar en placas simples y fácil es hacerlo con TC.

Los segmentos obstruidos del ID raramente exceden los cinco centímetros de diámetro si el cuadro es agudo, pero en obstrucciones a veces incompletas de larga data la dilatación puede llegar a un grado tal que simula obstrucción cólica.

Cuando existen dudas o quiere precisarse el punto de ubicación y etiología de la obstrucción del ID, puede emplearse sulfato de bario por vía oral (Figuras 12b, 13b, 14, 15b, 19b) Cuando se sospecha obstrucción de IG, no debe usarse sulfato de bario por vía oral porque se absorbe el agua en el colon y se forma una obstrucción sólida con piedras de bario. Puede utilizarse el contraste baritado en obstrucción de IG por vía rectal, que será fácil de eliminar y mostrará el nivel de obstrucción y muchas veces la causa.

La mayoría de las obstrucciones yeyunales distales e ileales ocurren en la pelvis y su sitio de bloqueo es raramente detectado por placas simples. Es riesgoso sugerir el punto exacto de oclusión basado en la distribución de gases, porque varias asas completamente llenas de líquido, generalmente se interponen proximales al sitio de bloqueo. Esto es aún más evidente cuando se tiene el mal hábito de tomar solo las Rx "de pie", ya que el gas migra a craneal y se ignoran las asas inundadas que bajan a la pelvis (Figuras 16,17).

La demostración de niveles hidroaéreos ha sido cuestionada por la mayoría de los expertos. Niveles hidroaéreos per se no indican oclusión. Pacientes con diarrea, puérperas y tomadores de laxantes tienen niveles hidroaéreos. Además las Rx expuestas con rayo horizontal (de pie) tienen menor calidad y menor información que las de decúbito supino, son más incómodas para el paciente y con mayor tasa de repetición por movimiento y factores técnicos.

Cuando el patrón gaseoso no es concluyente y no se dispone de TC, una Rx de control, minutos $\mathrm{u}$ horas después, clarifica la presencia y evolución del bloqueo intestinal, con mínimas molestias para el paciente.

\section{Obstrucción del intestino grueso}

La configuración típica de obstrucción mecáni- ca del IG es la dilatación de todos los segmentos proximales al punto de oclusión. A diferencia del ID, que sólo recibe gas deglutido vía transpilórica y regurgitada a través de la válvula ileocecal incompetente, el colon tiene producción endógena de gases por la descomposición bacteriana y fermentación fecal. Estos gases incluyen metano e hidrógeno y otros productos volátiles, pero el mayor componente del gas del colon es nitrógeno resultante de la deglución de aire. Por lo tanto en obstrucción del IG es la aerofagia la causa predominante de acumulación gaseosa.

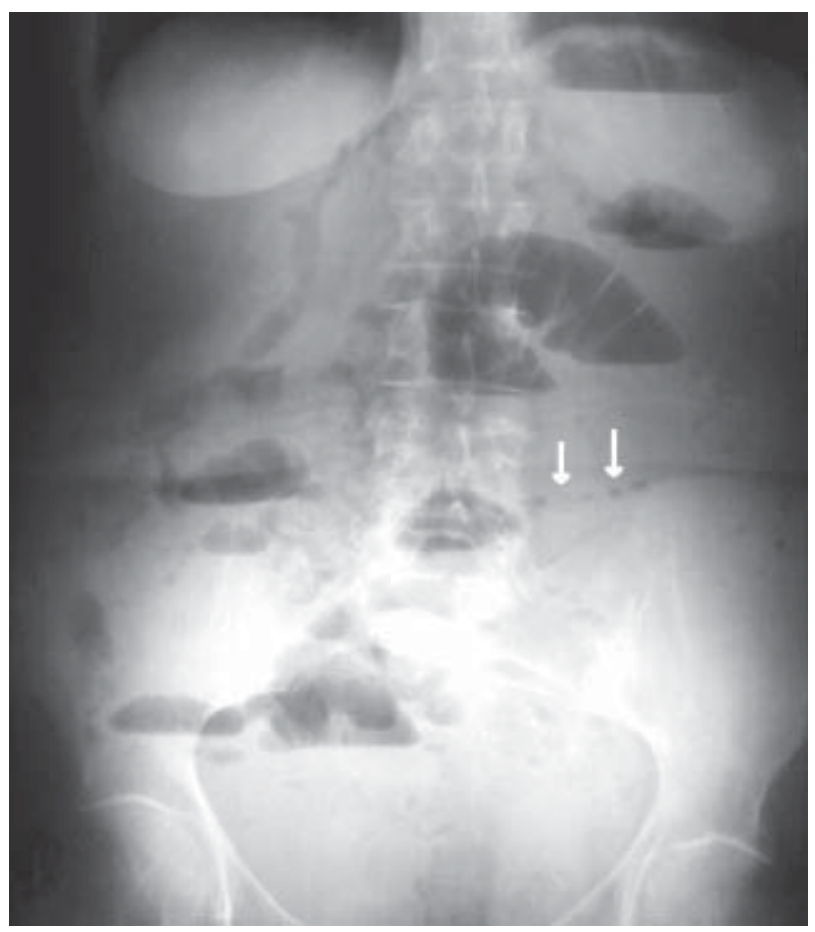

Figura 16. Abdomen simple. Asas dilatadas con nivel hidroaéreo. Distal se observa collar de perlas (flechas).

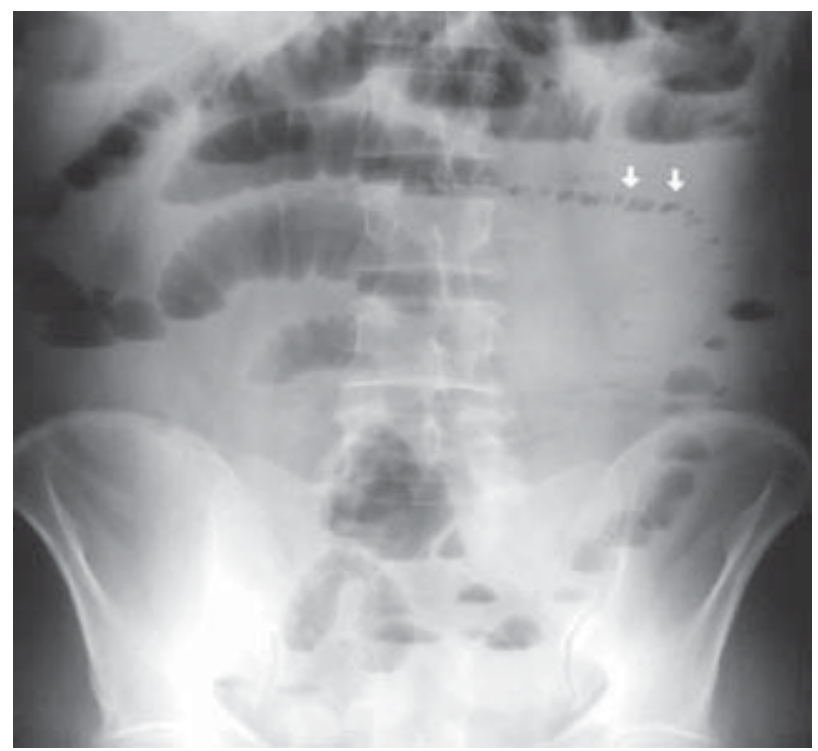

Figura 17. Abdomen simple. Niveles hidroaéreos y collar de perlas (flechas). 
Cuando el IG está distendido por gas y la válvula ileocecal impide el flujo retrógrado hacia el ileon, el diagnóstico de obstrucción intestinal en sencillo en las Rx simples de abdomen. Los segmentos cólicos, hasta el sitio del bloqueo luminal se destacan claramente y las plicas semicirculares que indentan el lumen están demarcadas en forma precisa. Sin embargo, tal apariencia es encontrada en una minoría de casos, ya que secreciones intestinales y material fecal también ocupan el lumen distendido. El IG completamente lleno de líquido puede no ser aparente en las Rx simples. Usualmente la combinación de gas y heces imparten una apariencia moteada al IG. La distensión del ciego es frecuente y cuando supera los 9 centímetros de diámetro hay riesgo de estallido cecal, no importando cual sea el punto de obstrucción del IG, porque la tensión parietal depende del cuadrado del radio (ley de Laplace) y el radio intestinal es máximo en el ciego.

En decúbito supino, el recto es el segmento más dependiente (de posición más baja) de todo el tubo digestivo y puede no contener gas porque las heces y los líquidos son más pesados y por lo tanto las proyecciones ánteroposteriores ventrodorsales no pueden diferenciar obstrucciones sigmoideas de íleos adinámicos. La placa en decúbito prono sitúa al recto en un plano más alto, permitiendo que los gases fluyan desde el sigmoides hacia el recto y con ello puede excluirse una obstrucción de sigmoides distal con certeza (Figura 18).

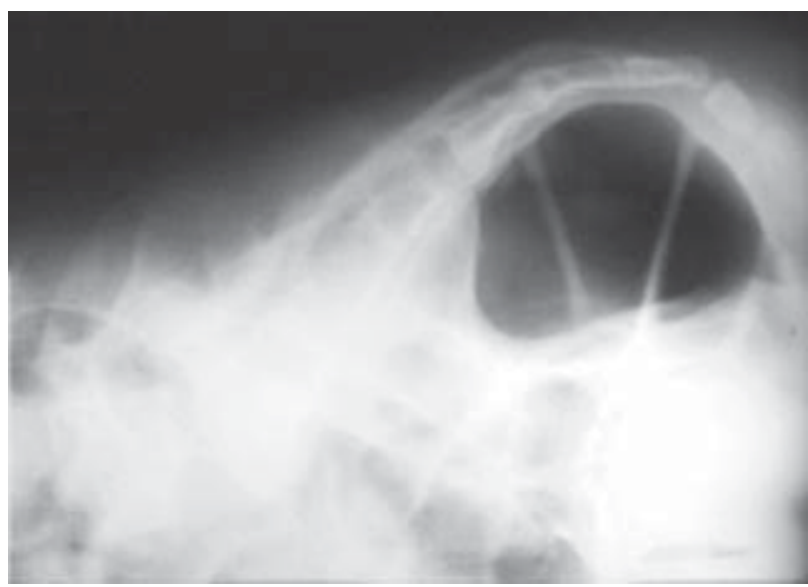

Figura 18. En procúbito el gas llena el recto y muestra válvulas de Houston.

Causas frecuentes de obstrucción del colon son: carcinomas, diverticulitis y vólvulos. Las adherencias son etiologías menos frecuentes que en el ID. Las hernias externas son frecuentes y las internas se observan raramente. Las oclusiones por obturación (con lumen totalmente ocupado e imagen en copa) producidas por íleos biliares (Figura 19), bezoares, cuerpos extraños deglutidos, fecalomas, etc. son más frecuentes en el ID, no obstante los íleos biliares y los cuerpos extraños si traspasan la válvula ileocecal pueden quedar atrapados en el sigmoides, ya que la diverticulosis que disminuye el calibre de este segmento cólico es cada día más prevalente.
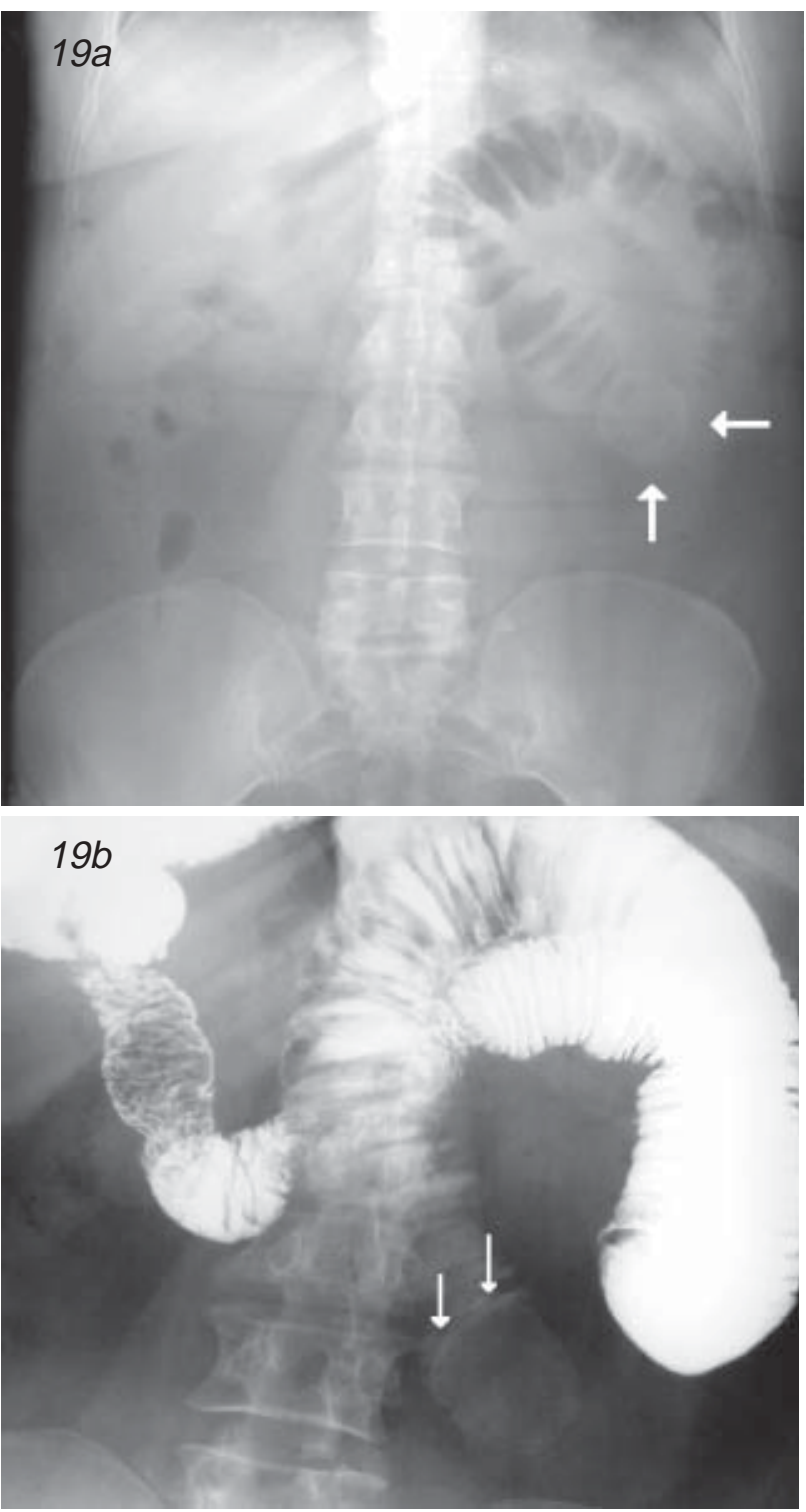

Figuras 19 a,b. Íleo biliar. a. Yeyuno dilatado. Válvulas conniventes estiradas y cálculo. (flechas) b. Examen contratado. Imagen en copa en el cálculo (flechas).

Los vólvulos de IG tienen imágenes características en las placas simples. El vólvulo cecal muestra el ciego dilatado, con abundante gas y haustras muy visibles (Figuras 15, 16 primera parte). Sus paredes son lisas y el ciego se sitúa en el abdomen medio o cuadrante superior izquierdo, a veces sobre impuesto o desplazando el estómago. Puede estar dilatado con gas el ID bajo que también esta ocluido por rotación. Dicha rotación (Figura 15 primera parte) determina isquemia por obstrucción inicialmente venosa. Es requisito para llegar a un vólvulo cecal un ciego móvil o vagabundo, con meso largo e intraperitoneal.

El vólvulo sigmoideo se produce en asas largas 
y dilatadas, lo que depende preferentemente de dietas ricas en fibra. Se reconoce en la placa simple el sigmoides aumentado de volumen y longitud porqué sale de la pelvis y llega a adosarse al colon transverso o incluso al diafragma.

La rotación axial en vólvulo sigmoideo varía entre 180 y 540 grados, por lo tanto es muy alta la incidencia de obstrucción vascular. El punto de rotación se sitúa sobre el sacro y promontorio y el asa distendida con líquido y mucho gas se eleva en línea media hacia el diafragma. Puede simular un pneumoperitoneo (Figura 13, primera parte). Puede lateralizarse a derecha o izquierda. El asa distendida no muestra haustras ni tabiques a diferencia del vólvulo cecal. Tiene una configuración en $U$ invertida. Como el vólvulo sigmoideo es una obstrucción en asa cerrada, el colon proximal a la obstrucción está bloqueado y dilatado y puede observarse dilatación de colon descendente transverso y derecho, lo que complica la interpretación de la imagen. Generalmente el ID no está dilatado. El asa sigmoidea dilatada produce la imagen característica de un gran grano de café (Figuras 20,21).

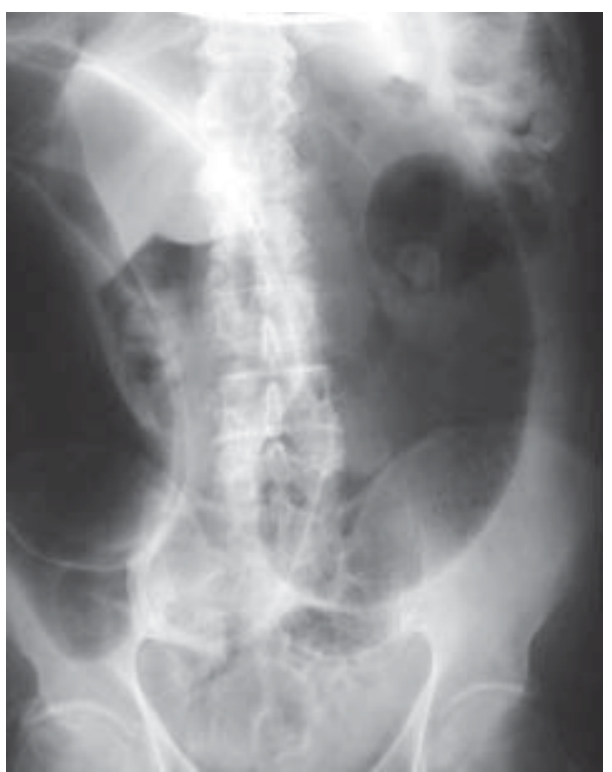

Figura 20. Abdomen simple. Gran grano de café. Vólvulo sigmoideo.
El vólvulo de colon transverso es muy poco frecuente pero su mortalidad es tres veces mayor que los vólvulos ya comentados. Requiere de un mesenterio laxo y una gran guirnalda de sigmoides. En placas simples no hay imágenes características. La TC es de gran ayuda aunque difícil de interpretar.

Vólvulos rarísimos son los de la flexura esplénica y el cecosigmoideo combinado.

\section{Colitis ulcerosa grave y megacolon tóxico.}

En el megacolon tóxico la Rx simple en decúbito dorsal es suficiente para hacer el diagnóstico y los exámenes contratados junto a la colonoscopía que insufla y distiende son de muy alto riesgo de perforación. El megacolon tóxico es una dilatación aguda segmentaria o total de comienzo brusco con dolor abdominal, diarrea, fiebre alta y compromiso del estado general.

En las Rx simples en decúbito supino el colon aparece dilatado y lo más notorio es el colon transverso o sigmoides, porque el gas asciende a las zonas más altas. La dilatación generalmente es moderada y siempre menor que la observada en vólvulo cecal. Casi de regla hay pocas heces en el segmento dilatado y las haustras están borradas y las plicas semicirculares se encuentran ausentes 0 engrosadas. El contorno presenta tosca nodularidad por pseudopólipos que protruyen al lumen. Si se expone como complemento una Rx en procúbito el gas migra a colon ascendente y descendente que quedan más altos y muestran sus lesiones parietales (Figuras 22,23).
Figuras 21 a,b. Vólvulo sigmoideo. a. $R x$ de pie. Niveles en el sigmoides dilatado. b: AP decúbito, enorme grano de café llena el abdomen.
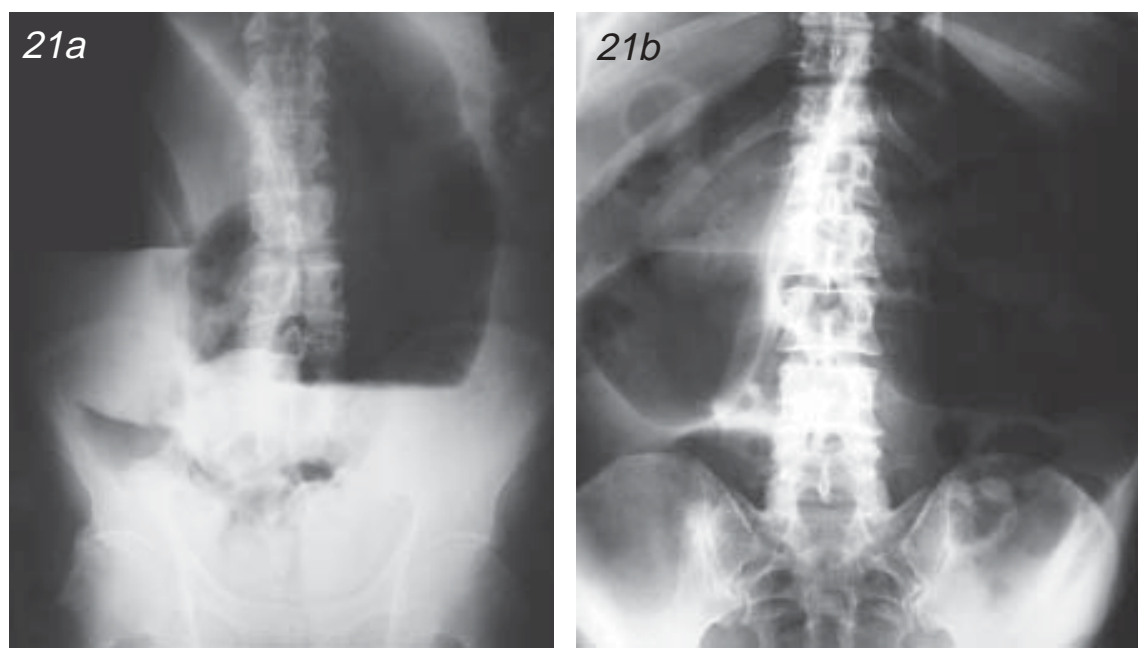

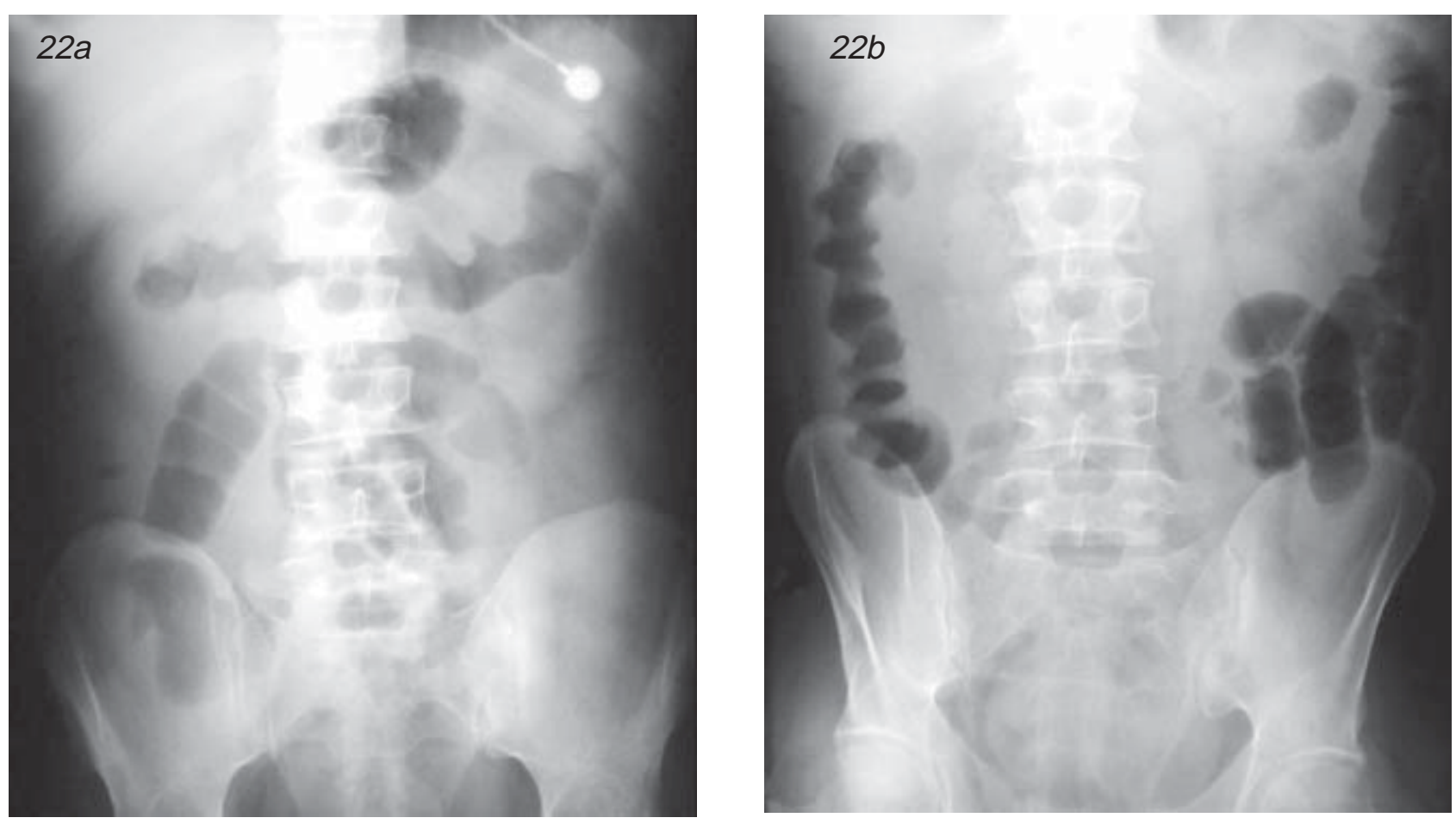

Figuras 22 a,b. Colitis ulcerosa grave. Abdomen simple. a. Decúbito supino. Colon transverso con pared engrosada y pseudopólipos. b. Procúbito. Gas migra hacia colon ascendente mostrando pancolitis hasta el ciego.

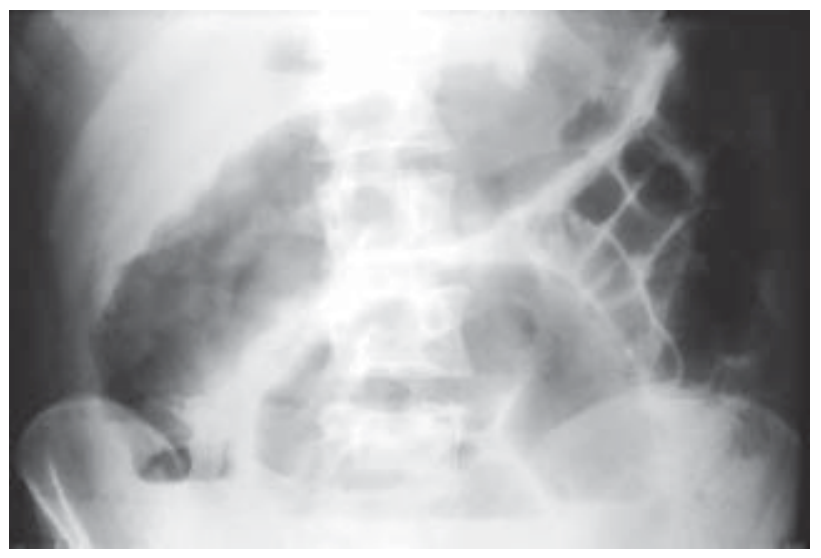

Figura 23. Abdomen simple. Megacolon tóxico. Pared engrosada. Falta de haustras y plicas. Nodularidad. Ausencia de deposiciones sólidas.

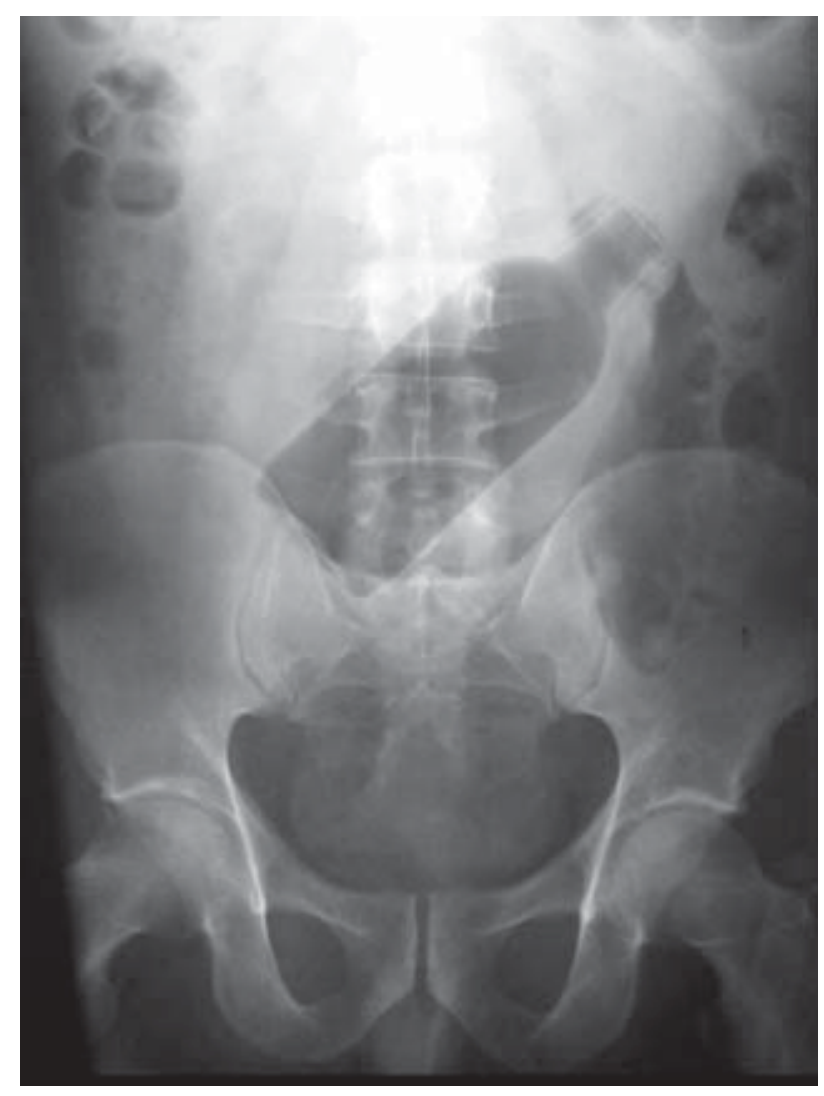

Figura 24. Abdomen simple. Envase de colonia de plástico, con gas en su interior. 
Figura 25. Abdomen simple. "Burrero" (condones con clorhidrato de cocaína).

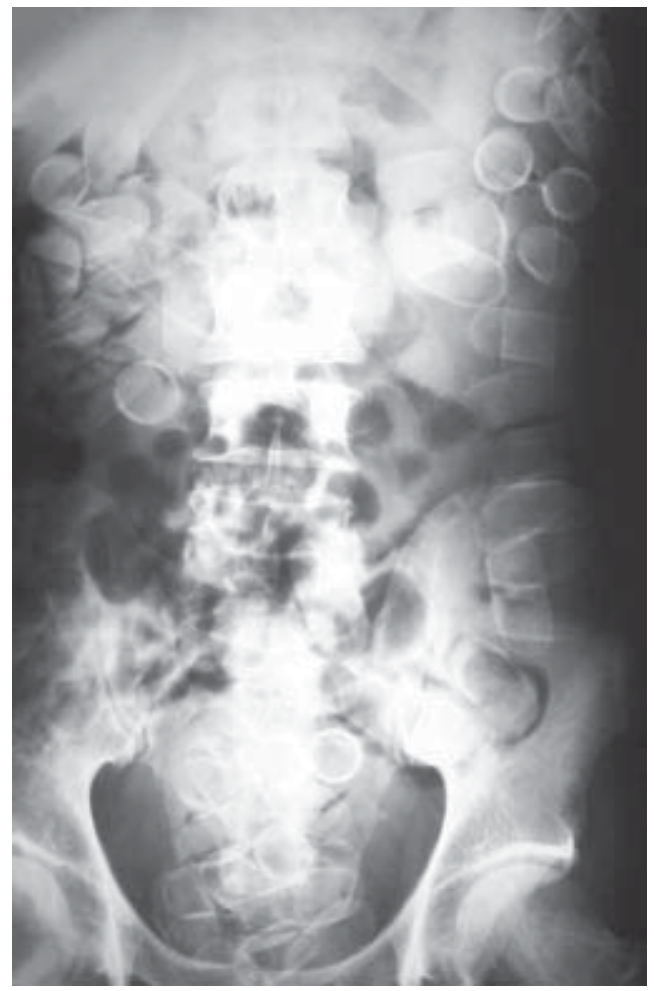

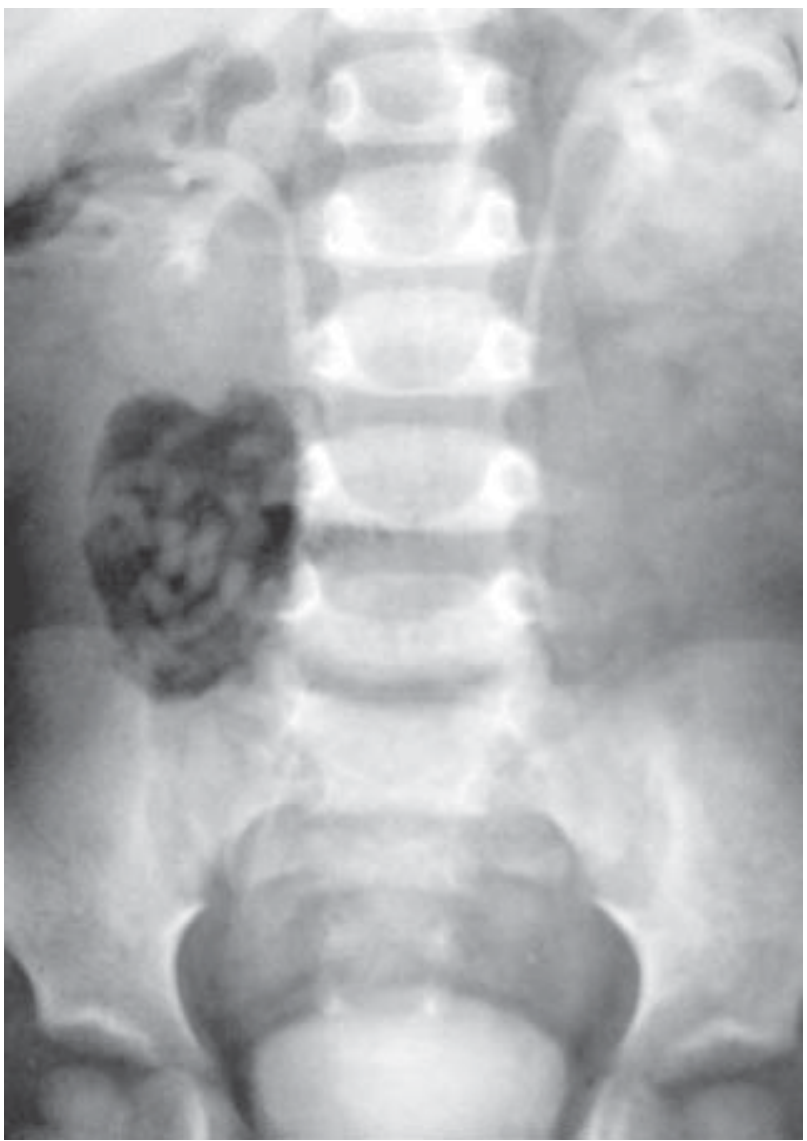

Figura 26. Abdomen simple. Ascaris lumbricoides en asa distendida con gas.

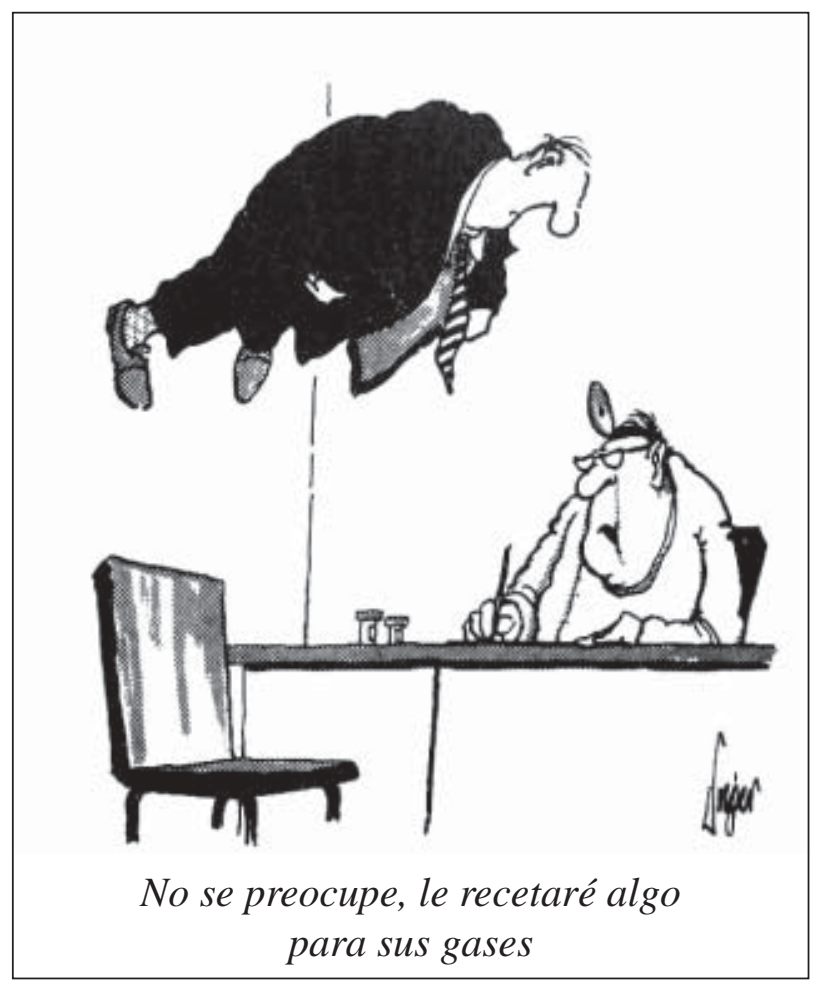


Aunque la causa más frecuente de megacolon tóxico es la colitis ulcerosa, imágenes idénticas se producen en colitis granulomatosa, amebiasis y colitis pseudomembranosa.

\section{Cuerpos extraños.}

Si contienen gas o son radio opacos su detección es sencilla (Figuras $24,25,26$ ). Si son voluminosos, cualquiera sea su densidad desplazan las heces y gases luminales y son identificables.

Agradecimientos: Al Editor Científico de la Revista de la Sociedad Chilena de Radiología, quien me invitó a colaborar con este tema. A mis colegas y becados del Hospital Clínico de la Universidad de Chile y de la Clínica Alemana. Finalmente, pero no menos importante a mi hija la Dra. Claudia Cortés quien efectuó toda la diagramación y producción de imágenes digitalizadas.

\section{Bibliografía}

1. Baker SR. The abdominal plain film. Appleton and Lange. Norwalk Connecticut USA. 1990.

2. Weissleder R, Wittemberg J. Primer of diagnostic imaging. Mosby USA. 1994.

3. Gore R, Levine M, Laufer I. Textbook of gastrointestinal radiology. W.B. Saunders Co, USA. 1994.

4. Bosker G, MD. Medicine is the best laugther. Mosby USA 1995.

5. Fontanarrosa. Fontanarrosa y los médicos. Ediciones de la Flor. S.R.L. Buenos Aires. Argentina 1996. 